\title{
The effects of water temperature, acoustic tag type, size at tagging, and surgeon experience on juvenile Chinook salmon (Oncorhynchus tshawytscha) tag retention and growth
}

Rebecca R. Robinson ${ }^{1 *} \mathbb{D}$, Jeremy Notch ${ }^{1}$, Alex McHuron ${ }^{1}$, Renae Logston ${ }^{1}$, Tom Pham ${ }^{1}$ and Arnold J. Ammann²

\begin{abstract}
Background: Acoustic telemetry is a widely used tool to study the movement and survival of juvenile fish and often requires a surgical procedure to implant the transmitter, which may impact overall fitness and survival following release. This is an important consideration when implementing large-scale acoustic telemetry projects aimed at estimating outmigration survival. The objective of this study was to examine the effects of water temperature, tag type, size at tagging, and surgeon experience on tag retention and growth rate of juvenile Chinook salmon (Oncorhynchus tshawytscha). We tagged 128 spring-run Chinook salmon (81-97 mm fork length, 5.2-10.0 g, tag burden 2.4-6.0\%) with one of two types of acoustic transmitters; a shorter, heavier model ('standard') and a longer, lighter model ('injectable'). Fish were tagged by either a novice or experienced surgeon. An additional 64 untagged fish served as a control group and were split between temperature treatments. Fish were reared in either cool (mean $13.4^{\circ} \mathrm{C}$ ) or warm (mean $17.8^{\circ} \mathrm{C}$ ) water for 60 days, prior to being euthanized, weighed and measured.
\end{abstract}

Results: Tag retention was similar for both transmitter types, but varied with water temperature, with significantly higher tag loss in the warm treatment $(21.9 \%, 14$ tags expelled), compared to the cold treatment $(7.8 \%, 5$ tags expelled). In the warm treatment, fish growth in the injectable tag group was significantly lower compared to the control group, and lower than the standard tag group, but not significantly lower. There was no significant difference between the control and standard tag groups for the warm treatment. In the cool temperature treatment, fish growth was not significantly different among any of the factors tested. Surgery time differed between surgeons; however, surgeon experience did not significantly affect tag shedding or growth.

Conclusion: Total tag loss was $14.8 \%$ over the 60 -day trial, with higher and earlier loss in the warmer treatment. Tag length may be a more important factor than tag weight in smaller size fish. This suggests that tag shedding is a significant factor to consider when estimating survival, as the actual survival rate may be higher than estimates based solely on receiver detections.

Keywords: Acoustic telemetry, Chinook salmon, Tag model, Surgeon experience, Temperature, Tag implantation, JSATS

\footnotetext{
*Correspondence: rebecca.robinson@noaa.gov

${ }^{1}$ Institute of Marine Sciences, University of California, Santa Cruz, USA

Full list of author information is available at the end of the article
}

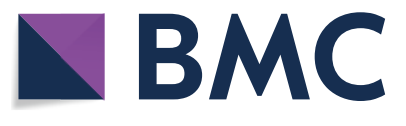

(c) The Author(s) 2021. This article is licensed under a Creative Commons Attribution 4.0 International License, which permits use, sharing, adaptation, distribution and reproduction in any medium or format, as long as you give appropriate credit to the original author(s) and the source, provide a link to the Creative Commons licence, and indicate if changes were made. The images or other third party material in this article are included in the article's Creative Commons licence, unless indicated otherwise in a credit line to the material. If material is not included in the article's Creative Commons licence and your intended use is not permitted by statutory regulation or exceeds the permitted use, you will need to obtain permission directly from the copyright holder. To view a copy of this licence, visit http://creativeco mmons.org/licenses/by/4.0/. The Creative Commons Public Domain Dedication waiver (http://creativecommons.org/publicdomain/ zero/1.0/) applies to the data made available in this article, unless otherwise stated in a credit line to the data. 


\section{Background}

In aquatic ecosystems where visually monitoring animals is challenging and sometimes impossible, acoustic telemetry provides the ability to track individuals over long distances and for extended periods of time. Acoustic telemetry has been used to monitor the movement and survival rates of many fish species including sturgeon [3, $30,38]$, rays $[4,9,41]$, and sharks [22, 24, 46]. It is also one of the most effective methods to study the movement and survival of juvenile Chinook salmon (Oncorhynchus tshawytscha) out-migrating from freshwater rearing areas to the Pacific Ocean [13, 32, 36, 53]. Other applications of acoustic telemetry include estimating the survival of juvenile salmon as they pass anthropogenic structures such as large water diversions [40] and understanding the migration routes through the California Delta $[6,7$, 39]. These studies provide resource managers with valuable seaward migration survival data which are critical in making well-informed water management decisions [14].

To monitor population-level movement, it is necessary to track individuals across all size ranges. With the development of the Juvenile Salmon Acoustic Telemetry System (JSATS, see [28], transmitters are now small enough to use in sub-yearling juvenile salmon. Further development resulted in a JSATS transmitter that was lighter and could be implanted by needle injection [16], potentially allowing studies to track movement patterns and estimate survival of even smaller fish (between 54 and $99 \mathrm{~mm}$ fork length) [19].

In California's Central Valley (CCV), acoustic telemetry is an effective tool to monitor juvenile salmon movement and survival rates as it allows for tracking individuals at high spatial resolutions, over long distances (300-500 river kilometers), and across diverse habitats [31]. Once released, fish with acoustic transmitters (henceforth tags) are assumed to exhibit similar movement and survival rates as untagged fish. However, the surgical procedure and presence of the transmitter (tag burden) may negatively affect the fitness of study fish [26]. Additionally, a fish may lose its tag (tag shedding) and be incorrectly assigned as a mortality, which may become more likely the longer a fish resides within the study reach. The failure to account for these fish will result in survival estimates biased low. Many studies have researched tag retention, survival, growth and fitness in acoustic tagged juvenile Chinook salmon [1, 2, 26, 33, 49] with some finding reduced growth [47], decreased swimming ability [11] or reduced survival [52], while others have found no effect on growth or survivorship $[1,2]$. These discrepancies between study results of tag retention, growth, swimming ability, and survival, make it clear that further research is needed to understand the short and longterm effects of acoustic tagging.
We examined four factors known to exacerbate tagging effects following tag implantation in juvenile Chinook salmon, which included: water temperature $[8$, $18,37,51]$, surgeon experience $[12,18]$, size at tagging $[5,27,50]$, and tag type $[17,25]$. We hypothesized that water temperature may impact tag retention and growth and therefore to examine this, we held fish at one of two water temperatures similar to those experienced by juvenile salmon during seaward migration in the CCV. We also hypothesized that surgeon experience may affect tag retention and growth rates. To test this, we compared tag retention and growth rates of fish tagged by either an 'expert' or 'novice' surgeon. Size at tagging may also impact fish growth and tag retention therefore to examine this we tagged fish across a range of sizes to establish a minimum size recommendation. Currently, the two smallest commercially available JSATS tags present a choice between a lighter but longer tag versus a heavier but shorter tag. Due to the lighter weight, we would predict that the injectable tag would have reduced negative tag effects, however the longer shape may alter this. Tag shape is not well studied and may be an important factor when tagging small fish. We addressed this question by comparing tag retention, growth and survival in juvenile salmon across a range of sizes.

\section{Methods}

\section{Fish acquisition}

We acquired 192 juvenile spring-run Chinook salmon of fork length (FL) 81-97 mm on 4/18/2019 from the Feather River Fish Hatchery in Oroville, California, USA. Fish were selected to provide a range in sizes that are similar to the mean FL of $88.5 \mathrm{~mm}$ for trawl caught juvenile Chinook salmon leaving the Sacramento-San Joaquin Delta ("Delta Juvenile Fish Monitoring Program-Chipps Island trawls CHN-POD species 2012Present" n.d. [15]). While at the hatchery, fish were reared in water temperature of $9-11{ }^{\circ} \mathrm{C}$, during transport water temperature was maintained at $9.5-11.3{ }^{\circ} \mathrm{C}$. We transported fish to the Southwest Fisheries Science Center in Santa Cruz, CA and randomly divided them to one of two temperature treatments, $\operatorname{cool}\left(13.4{ }^{\circ} \mathrm{C}\right)$ or warm $\left(17.8^{\circ} \mathrm{C}\right)$. These temperatures are representative of those experienced by out-migrating juvenile salmon in the Sacramento River; the largest salmon producing river in California [55]. We placed the fish assigned to the cool treatment directly into the cool-water tanks upon arrival. Fish assigned to the warm treatment were gradually acclimated to the warmer water temperature over a period of 3 days to avoid thermal stress. To further reduce stress due to travel and temperature acclimation, we held fish in their respective temperature treatment for 3 days prior to surgery. 


\section{Treatments}

We randomly assigned fish to one of two surgeons who were classified as 'expert' or 'novice' based on their surgical tagging experience level. The expert surgeon's experience included implanting acoustic tags in over 2100 juvenile Chinook salmon, while the novice surgeon's experience included training but no actual tag implantation surgeries. Prior to implanting acoustic tags, we injected all fish with a standard size $(1.2 \mathrm{~mm} \times 2.7 \mathrm{~mm}$, weight negligible) Visible Implant Alphanumeric (VIA) Tags (manufactured by Northwest Marine Technology, Inc.) next to the dorsal insertion. This allowed individual identification of fish to determine individual growth rates. We assigned fish to one of three tag groups: control (no acoustic tag), standard tag (model SS300 with 337 battery, Advanced Telemetry Systems, Isanti, $\mathrm{MN}$ ), or injectable tag (model SS400 with BR306 battery, Advanced Telemetry Systems, Isanti, MN) (Fig. 1). Each standard tag was $10.7 \mathrm{~mm}$ long, $5.3 \mathrm{~mm}$ high, $3.0 \mathrm{~mm}$ wide, weighed $306 \mathrm{mg}$ in air and had a volume of $0.170 \mathrm{~mL}$. Each injectable tag was $15.0 \mathrm{~mm}$ long, $3.3 \mathrm{~mm}$ diameter, weighed $210 \mathrm{mg}$ in air and had a volume of $0.128 \mathrm{~mL}$. There were 16 fish assigned to each factor tested (water temperature, surgeon experience, and tag type). Fish size was randomly selected for each group. Prior to and following surgery, fish were not fed for $24 \mathrm{~h}$.

\section{Tagging}

All fish went through a similar surgical procedure including anesthesia, handling time (weighed, measured, and time on the surgical board), and recovery time. During the surgical process, fish were anesthetized in a bath of $90 \mathrm{mg} \mathrm{L}^{-1}$ tricaine methanesulfonate (MS-222) buffered with $360 \mathrm{mg} \mathrm{L}^{-1}$ sodium bicarbonate until they lost equilibrium. Each fish was weighed, measured for FL, injected with a VIA tag, and placed ventral side up on a foam surgery cradle. While in the cradle, the fish's gills were irrigated with a continuous flow of anesthetic bath (30 mg L ${ }^{-1}$ MS-222 buffered with $120 \mathrm{mg} \mathrm{L}^{-1}$ sodium bicarbonate). An incision was made anterior to the pelvic girdle and about $3 \mathrm{~mm}$ off the ventral midline using a microsurgical knife $\left(15^{\circ}\right.$ straight stab $3 \mathrm{~mm}$ blade). For the standard tag group, we made an incision approximately $6 \mathrm{~mm}$ long, inserted the transmitter through the incision into the coelom and then closed the incision with two interrupted sutures secured with a surgeon's knot using absorbable monofilament sutures (Unify PDO 6-0). For the injectable tag group, we made a 4-mm-long incision in the same location and inserted an injectable tag through the incision site into the coelom. This smaller incision was closed with a single suture. Prior to insertion, we disinfected all tags by soaking them in a $0.1 \%$

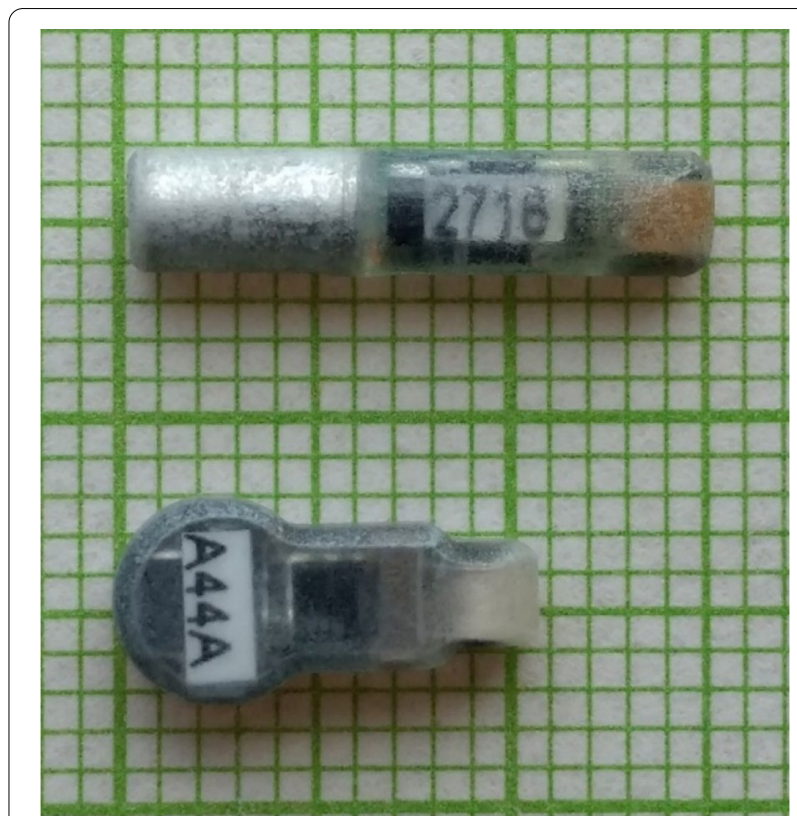

Fig. 1 The two types of Juvenile Salmon Acoustic Telemetry System transmitters; injectable (above, $210 \mathrm{mg}$ ) and standard (below, $306 \mathrm{mg}$ ). Each grid cell is $1 \mathrm{~mm} \times 1 \mathrm{~mm}$

solution of chlorhexidine diacetate and then triple-rinsing them in distilled water before implanting.

Surgery time was measured for each fish and was used to determine differences in surgeon experience. Control fish were anesthetized and place in the cradle and given a 'handling time' similar to acoustic tagged fish based on tag type and surgeon. Surgery time, or 'handling time' for control fish, included weighing, measuring, visual examination, implantation of VIA or acoustic tag. After tag implantation, we placed fish into the recovery bath and held them until they were swimming normally (average recovery time $\sim 2 \mathrm{~min}$ ) at which point we transferred them to their assigned temperature treatment tank. We monitored water temperature and dissolved oxygen in the surgery bath, drug bath, and recovery bath and kept the water temperature consistent to the assigned temperature treatments for each fish.

\section{Fish holding}

We split fish evenly between four indoor circular tanks $(91 \mathrm{~cm}$ high $\times 73 \mathrm{~cm}$ diameter, $490 \mathrm{~L}$ ) provided with flow-thru filtered freshwater and overhead lighting that mimicked the natural photoperiod. A piece of wood tied with lengths of rope was placed into each tank to provide structure. Two tanks were maintained as 'cool' tanks (mean water temperature of $13.4{ }^{\circ} \mathrm{C}$, range 11 to $17{ }^{\circ} \mathrm{C}$, SD 1.17) and two as 'warm' tanks (mean water temperature of $17.8{ }^{\circ} \mathrm{C}$, range 14 to $23^{\circ} \mathrm{C}$, SD 1.04). Temperatures 
were held stable except for a spike in the cool tank due to a chiller failure on day 36 and an unusually large increase in ambient air temperature on day 50, which resulted in higher temperatures in both treatments. We checked tanks daily for shed tags using a magnet sweeper and cleaned every other day or as needed using a siphon. Any mortalities were removed and frozen.

Prior to surgery, we fed fish commercial food pellets at $2 \%$ tank biomass per day. After surgery, we fed fish $2 \%$ and $3.2 \%$ tank biomass per day for the cool and warm treatments, respectively. The increase in feeding rate for the warm treatment was intended to equalize growth rate between the two temperature treatments by compensating for the higher metabolic rate of fish in warmer water. Daily feed amounts were increased by $1.5 \%$ each week.

We tested for differences in initial weight and FL between the three tag treatments in each of the two water temperatures using a two-way ANOVA and found that they were not significantly different for either the warm or cool temperature treatments (Table 1.). At the end of the 60-day trial, we removed all fish and euthanized them with an overdose of MS-222. Fish were individually identified based on their VIA tag or by reading the label on their acoustic tag. We then photographed, weighed, and measured each fish. Acoustic tagged fish were dissected, the presence or absence of an acoustic tag was recorded, and the overall condition of the fish was noted.

\section{Statistical analysis}

We used a proportional hazards regression (Cox regression, package coxme) in $R$ statistical software, version 3.3.0 ( $\mathrm{R}$ Core Team, 2019) to test for differences in tag loss between water temperature, surgeon experience, size at tagging, and tag type. Proportional hazard models are frequently used in medical studies to examine the effect of multiple factors on the time to an event (e.g., recovering from an illness). Since we were interested in how the above predictors would affect loss of fish from a field study, we considered a fish as lost from the trial if it shed its tag or if it died. Therefore, the time to event for our trial was the time to tag shedding or time to mortality, which we refer to collectively as tag loss rate. Due to the small sample size for the size range of fish used in this study, we binned starting fish size into three groups and tested it as a categorical variable using the following categories: small (81-85), medium (86-90), large (91-97 mm FL).

We analyzed differences in individual fish growth for surgeon experience, size at tagging (small, medium, or large) and tag type in R using a three-way ANOVA (package car). For each fish that survived to the end of the study, we calculated the specific growth rate (SGR) of weight [23]:

$$
\mathrm{SGR}=\left(\operatorname{Ln}\left(\mathrm{w}_{\mathrm{t}}\right)-\operatorname{Ln}\left(\mathrm{w}_{\mathrm{i}}\right)\right) / t \times 100,
$$

where $\operatorname{Ln}\left(w_{t}\right)$ is the natural logarithm of the weight at time $t$ and $\operatorname{Ln}\left(\mathrm{w}_{\mathrm{i}}\right)$ is the natural logarithm of the initial weight. Thus, SGR is expressed as \% change in weight per day. We analyzed each temperature treatment separately because growth rate is a function of temperature. To investigate differences in growth between the three tag treatments, we used a post hoc Tukey honest significant difference (package stats) test. The post hoc test allowed us to analyze if growth significantly varied between the three tag types. We tested the assumptions of the ANOVA using the Shapiro test and the Levene test (package car).

\section{Results}

Mean tag burden by weight (tag weight/fish weight) was higher for standard tags compared to injectable tags (cool: $4.1 \%$ and $3.2 \%$; warm $4.4 \%$ and 3.2\%). However, tag

Table 1 Initial weight, fork length, tag burden for weight (tag weight/fish weight) and tag burden for length (tag length/fish length) for juvenile Chinook salmon in three tag treatments (control, standard and injectable) two temperature treatments; cool (13.4 $\left.{ }^{\circ} \mathrm{C}\right)$ and warm $\left(17.8^{\circ} \mathrm{C}\right)$, and two surgeons (novice and experienced)

\begin{tabular}{|c|c|c|c|c|c|c|c|c|c|}
\hline \multirow[t]{2}{*}{ Tag treatment } & \multirow[t]{2}{*}{$n$} & \multicolumn{2}{|l|}{ Weight (g) } & \multicolumn{2}{|c|}{ Fork length (mm) } & \multicolumn{2}{|c|}{ Tag burden weight (\%) } & \multicolumn{2}{|c|}{ Tag burden length (\%) } \\
\hline & & Mean $\pm S D$ & Range & Mean \pm SD & Range & Mean \pm SD & Range & Mean \pm SD & Range \\
\hline \multicolumn{10}{|c|}{ Cool temperature } \\
\hline Control & 32 & $7.0 \pm 1.0$ & $5.2-8.7$ & $86.7 \pm 4.0$ & $81-93$ & & & & \\
\hline Standard & 32 & $7.4 \pm 1.1$ & $5.8-10.0$ & $87.9 \pm 4.3$ & $81-97$ & $4.14 \pm 0.6$ & $3.0-5.2$ & $12.2 \pm 0.6$ & $11.0-13.2$ \\
\hline Injectable & 32 & $7.2 \pm 1.0$ & $5.6-9.4$ & $87.4 \pm 3.6$ & $81-93$ & $3.1 \pm 0.4$ & $2.3-3.9$ & $17.2 \pm 0.7$ & $16.1-18.5$ \\
\hline \multicolumn{10}{|c|}{ Warm temperature } \\
\hline Reference & 32 & $7.1 \pm 1.0$ & $5.6-8.9$ & $87.3 \pm 3.7$ & $81-94$ & & & & \\
\hline Standard & 32 & $7.0 \pm 1.1$ & $5.3-9.3$ & $86.9 \pm 3.7$ & $81-94$ & $4.4 \pm 0.7$ & $3.2-5.7$ & $12.3 \pm 0.5$ & $11.4-13.2$ \\
\hline Injectable & 32 & $7.0 \pm 0.7$ & $5.8-8.1$ & $86.8 \pm 2.5$ & $82-92$ & $3.2 \pm 0.3$ & $2.7-3.8$ & $17.3 \pm 0.5$ & $16.3-18.3$ \\
\hline
\end{tabular}


burden by length (tag length/fish length) was higher for injectable compared to standard tag types (cool: 17.2\% and $12.2 \%$; warm $17.3 \%$ and $12.3 \%$ ) (Table 1).

Tag loss Over the course of the 60-day trial, 19 out of 128 (14.8\%) fish expelled their tags. We recovered all shed tags on the day shedding occurred, except for one (cool temperature treatment), which was found in the drainage assembly at the end of the trial. The exact shed date of this tag is unknown but leaving it out could bias the shedding rate, so the date expelled for this tag was imputed based on the average shed date for standard tag/ cool temperature treatment. Both tag types had similar loss rates; $15.6 \%$ of standard (10 tags, shed on day 12 , $18,20,22,23,29,34,41,46$ and 59$)$ and $14.1 \%$ of injectable (9 tags, shed on day 14(2), 20, 29, 34, 42, 45, 46 and 54). There were two mortalities in the control group (day 11, day 41), one in the standard tag treatment, four in the injectable tag treatment (Table 2). All five tagged fish mortalities were tagged by the novice surgeon, while the control fish mortalities were handled by the experienced surgeon. One of the control group mortalities was likely due to tail rot. One tagged fish mortality shed its tag prior to death, the other four did not shed their tags. Total loss rate (shed tags + mortalities) for standard and injectable tag type was lower for the large size bin (5.6 and $9.1 \%$ ) compared to the medium (25.0 and $18.2 \%)$ and small (18.2 and 23.8\%) size bins, respectively (Table 3). However, size class was not a significant factor in determining tag shed rate in our study.
The proportional hazards model found that water temperature significantly affected tag shedding $(p=0.028)$ with warm treatment fish $(28.1 \%, 14$ tags shed plus 4 tagged mortalities) more likely to lose a tag, either through shedding or mortalities, than cool treatment fish (9.4\%, 5 tags shed plus 1 tagged mortality). Additionally, three out of the four shed events in the cool temperature treatment occurred after day 45 , while tags were shed consistently in the warm temperature treatment after day 12 (Fig. 2). Tag shedding did not significantly differ between surgeon experience $(p=0.285)$, size at tagging (medium $p=0.226$, small $p=0.866$ ), or tag model $(p=0.866)$.

Growth in warm treatment Over the course of the 60-day study, fork length increased on average by $36.5 \mathrm{~mm}(\mathrm{SD} \pm 12.1 \mathrm{~mm})$ and fish weight increased by $12.9 \mathrm{~g}(\mathrm{SD} \pm 8.5 \mathrm{~g})$. Specific growth rate varied significantly by tag treatment $(p=0.005)$, with injectable tag fish $(1.75 \pm 0.63)$ having significantly lower growth than control fish $(p=0.003,2.22 \pm 0.44)$, and lower but nonsignificant growth than standard tag fish $(p=0.108$, $2.03 \pm 0.54)$. There was no difference in growth between standard tag and control fish $(p=0.345)$. Starting size did not significantly affect growth $(p=0.387)$.

Growth in cool treatment Over the course of the 60-day study, fork length increased on average by $26.9 \mathrm{~mm}$ $( \pm 12.5 \mathrm{~mm})$ and fish weight increased by $11.6 \mathrm{~g}( \pm 7.5 \mathrm{~g})$. Starting size $(p=0.493)$ and tag model $(p=0.209)$ did not affect growth in the cool temperature treatment.

Table 2 Tag shedding and mortality over 60 days for three tag groups of juvenile Chinook salmon reared at two temperatures: cool (mean $13.4^{\circ} \mathrm{C}$ ) and warm $\left(17.8^{\circ} \mathrm{C}\right)$

\begin{tabular}{|c|c|c|c|c|c|c|}
\hline Temperature & Tag group & $n$ & Shed tags & Mortality & Total lost & Total lost (\%) \\
\hline Cool & Control & 32 & na & 2 & 2 & 6.3 \\
\hline Cool & Standard & 32 & 4 & 1 & 5 & 15.6 \\
\hline Cool & Injectable & 32 & 1 & 0 & 1 & 3.1 \\
\hline Warm & Control & 32 & na & 0 & 0 & 0.0 \\
\hline Warm & Standard & 32 & 6 & 0 & 6 & 18.8 \\
\hline Warm & Injectable & 32 & 8 & 4 & 12 & 37.5 \\
\hline
\end{tabular}

Total lost are combined tags shed and mortalities for each tag group and temperature treatment. na: not applicable as control fish did not receive an acoustic tag

Table 3 Tag shedding and mortality after 60 days for three size bins (initial fork length ( $\mathrm{mm}$ )) of juvenile Chinook salmon implanted with acoustic transmitters

\begin{tabular}{lllllcc}
\hline $\begin{array}{l}\text { Size bin (mm, FL } \\
\text { range) }\end{array}$ & $\boldsymbol{n}$ & $\begin{array}{l}\text { Fork length }(\mathbf{m m}, \\
\text { mean } \pm \text { SD) }\end{array}$ & $\begin{array}{l}\text { Weight }(\mathbf{g}, \\
\text { mean } \pm \text { SD) }\end{array}$ & Shed tags & Mortality & Total lost \\
\hline $81-85$ & 43 & $83.2 \pm 1.4$ & $6.1 \pm 0.4$ & 8 & 1 & 9 \\
$86-90$ & 56 & $87.9 \pm 1.4$ & $7.2 \pm 0.5$ & 10 & 3 & 13 \\
$91-97$ & 29 & $92.1 \pm 1.3$ & $8.5 \pm 0.6$ & 1 & 1 & 23.2
\end{tabular}

Data pooled form two temperature treatments and two tag types. Total lost are combined tags shed and mortality for each size bin for 


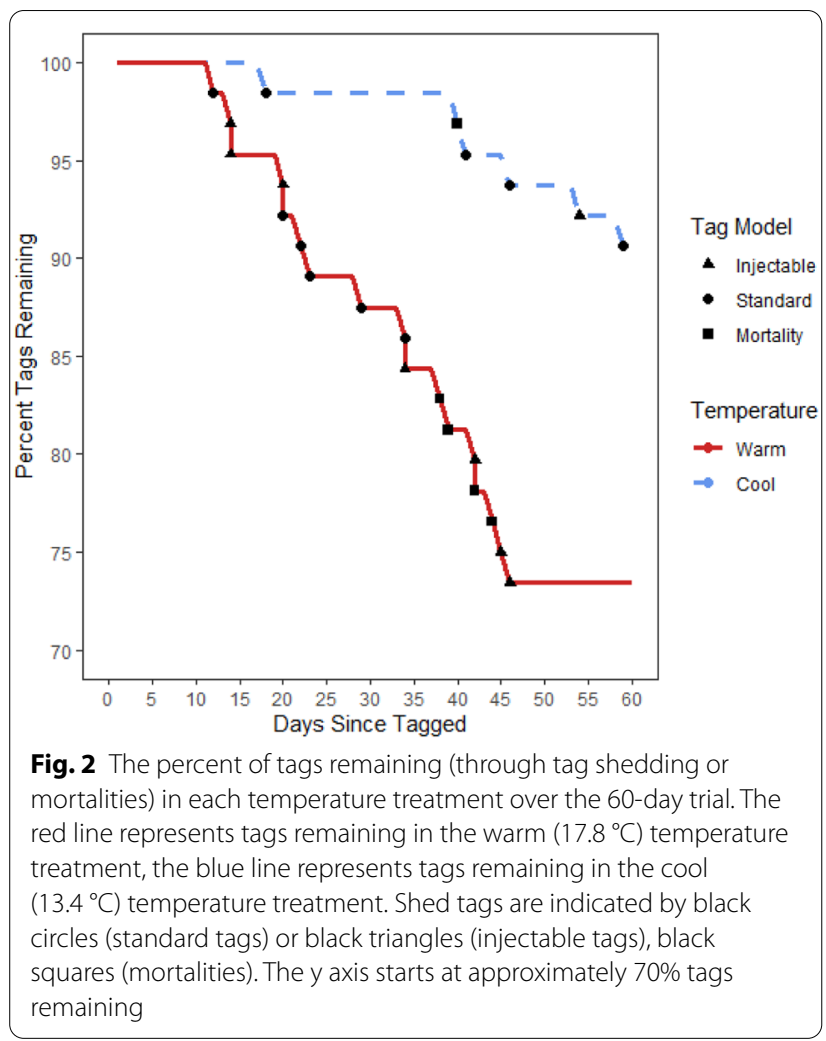

Surgeon experience While there were significant differences in surgery time between the two surgeons for each tag type (ANOVA, injectable tag $p<2.2 \mathrm{e}-16$, standard tag $p<2.2 \mathrm{e}-16$ ), we found no effect of surgeon experience on tag retention. The mean surgery time of the standard tag was $2.2( \pm 0.3)$ minutes (expert surgeon) and $3.9( \pm 0.6)$ minutes (novice surgeon). For the injectable tag, the mean surgery time was 1.4 $( \pm 0.3)$ minutes (expert surgeon) and $2.8( \pm 0.5)$ minutes (novice surgeon). Tag shedding was similar for both surgeons; 9 tags (7 standard and 2 injectable) were shed by fish tagged by the expert surgeon, 10 tags (3 standard and 7 injectable) from the novice surgeon. Surgeon experience did not affect growth in either the warm $(p=0.234)$ or cool $(p=0.189)$ temperature treatment (Fig. 3). Surgery time also differed for both surgeons between the warm and cool treatment (ANOVA, experienced surgeon $p=0.015$, novice surgeon $p=0.015)$ with slower surgery times in the cool treatment (mean $1.9( \pm 0.5)$ minutes, mean $3.7( \pm 0.7)$ minutes) than the warm treatment fish (mean $1.7( \pm 0.4)$ minutes, mean $3.3( \pm 0.9)$ minutes) for the experienced and novice surgeon, respectively.

\section{Discussion}

In this study, we measured tag retention and growth in juvenile Chinook salmon implanted with one of two acoustic transmitters of different size and weights, by surgeons of varying levels of experience, and reared at two different water temperatures. Fish reared in warmer water temperatures (mean of $17.8{ }^{\circ} \mathrm{C}$ ) had earlier and significantly higher tag shedding rates; $21.9 \%$ compared to $7.8 \%$ in cooler water (mean of $13.4{ }^{\circ} \mathrm{C}$ ). This is consistent with other studies finding increased tag loss in warmer temperature for Chinook salmon juveniles [18, 42]. The effect of temperature may be due to the suppression of the immune response [34] in cooler temperatures, including the foreign body response of rejecting an implanted tag. This suggests that warm temperatures significantly affect the tag retention rates in juvenile salmon and should be considered when conducting acoustic telemetry studies. In the lower Sacramento River, water temperature often exceeds $17.8^{\circ} \mathrm{C}$ beginning in April; a time in the year when a significant proportion of juvenile spring-run Chinook salmon smolts out-migrate [36].

The time it takes for tag shedding to occur after fish are implanted with tags is an important factor that will affect how tag shedding rates are applied in field studies. In the $\mathrm{CCV}$, acoustic telemetry studies on Chinook smolts have shown some fish to out-migrate in 22 days [31]. While there was no tag shedding in our study until day 12 , our study had $5.5 \%$ of tags shed prior to day 22 in the warm temperature treatment. This indicates that shedding may impact survival estimates for even quickly out-migrating populations. Other populations of salmon, such as Sacramento River winter-run, have been shown to take upwards of 40 days [43] to out-migrate through the CCV, although under different water conditions compared to spring-run juveniles, which may result in survival estimates biased low as a result of tag shedding.

The shedding rate was similar between the two tag types. This was a surprising result as the standard tag type weighed $30 \%$ more than the injectable tag type. Most previous studies have demonstrated that increasing tag burden, usually defined as the ratio of tag weight to fish weight, increases tag shedding [26, 27]. However, the lack of a difference in tag shedding between tag types in this study could be due to injectable tags being $40 \%$ longer than the standard tag ( 15 vs. $10.7 \mathrm{~mm}$ ). The increased length of the transmitter may have contributed to tag expulsion, by increasing the pressure of the tag against the body wall in a fish with a body cavity just large enough to accommodate the transmitter. This finding indicates that the relative length and shape of the transmitter, and not just the tag weight, should be considered when selecting a transmitter to implant in fish. Most studies select the minimum fish size using tag 


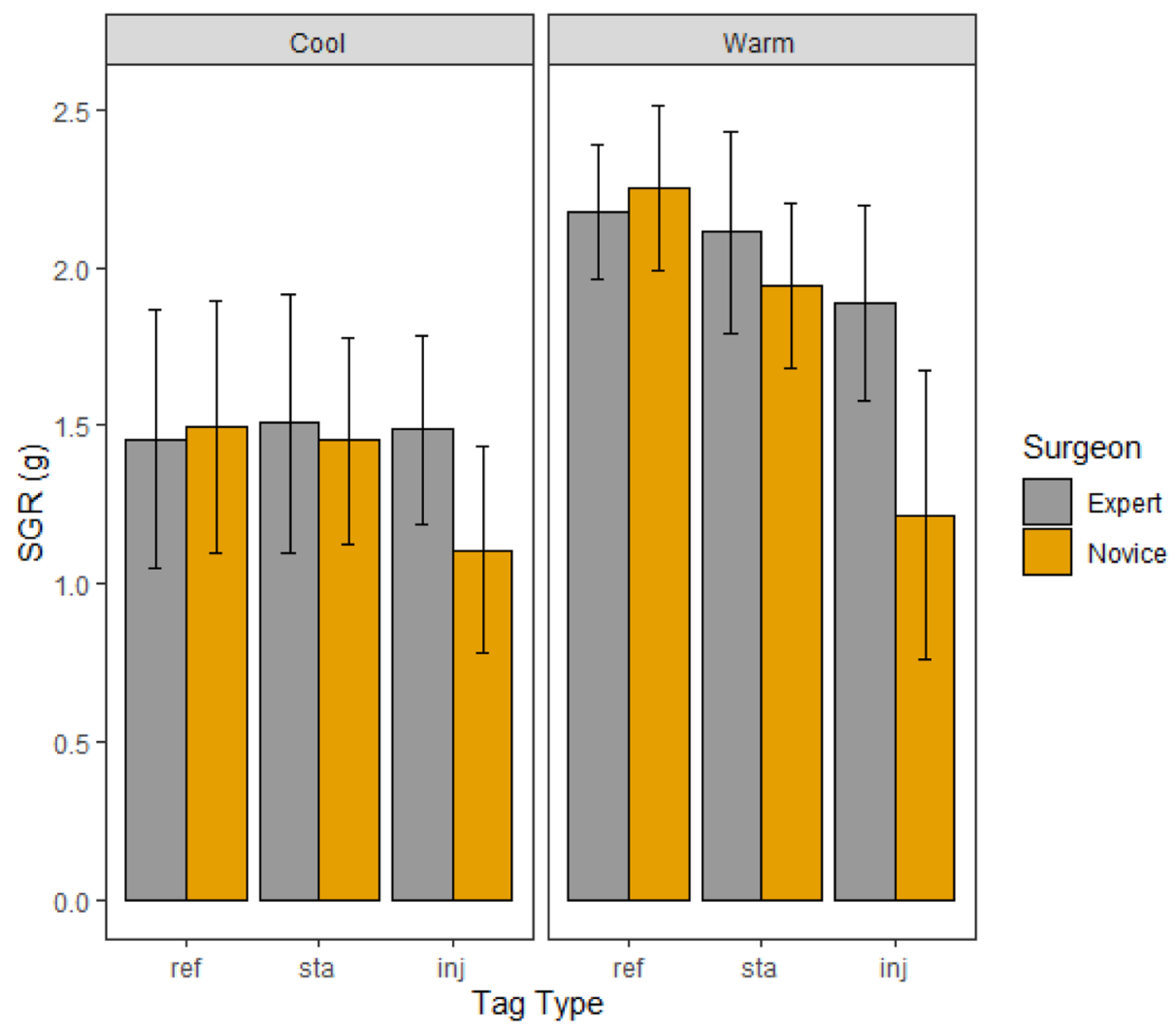

Fig. 3 Mean specific growth rate (with 95\% confidence interval) for weight (\% change per day) for the two surgeons (expert and novice) and three tag treatments (reference, injectable acoustic tag, standard acoustic tag) for the warm (mean $17.8^{\circ} \mathrm{C}$ ) and cool (mean $13.4^{\circ} \mathrm{C}$ ) temperature treatment

burden by weight. These results suggest that tag burden by length should also be considered when using longer injectable tags.

Many studies have addressed the minimum fish size for successful implanting of acoustic tags [5, 19, 20, 50]. Some studies recommend a minimum of $95 \mathrm{~mm}$ FL for juvenile Chinook salmon implanted with both a JSATS and PIT tag $[21,29]$. We used a range of fish sizes in our study (81-97 mm FL), but did not find a statistically significant effect of fish size on tag shedding. However, the combined tag shedding and mortality rate was two to four times higher in fish less than $91 \mathrm{~mm}$ FL compared to fish between 91 and $97 \mathrm{~mm}$ FL. Although we were not able to identify a statistically significant threshold for tag retention, likely due to a small sample size of fish in the large size class, our results suggest that implanting similar acoustic tags into fish greater than $90 \mathrm{~mm}$ (tag burden 2.4-4.2, 11.0-16.4) FL will substantially reduce tag shedding. When smaller fish are tagged, it is advisable to include a study examining survival and tag shedding for the size group of fish tagged in order to correct for tag loss.
We predicted that the injectable tag would have less of an impact on growth than the standard tag but, contrary to our expectation, fish with the lighter but longer injectable tag experienced decreased growth compared to fish with the heavier but shorter standard tag. Overall, growth was higher in the warm temperature treatment, however, fish tagged with the injectable tag in the warm temperature treatment had significantly reduced growth compared to control fish. Within the cool temperature treatment, we see a similar trend with injectable tagged fish having relatively, but not significantly, lower growth whereas there was no significant difference in growth rate for the standard tag group and the control group in either temperature. The only field study that directly compares survival of groups of juvenile salmon implanted with injectable or standard JSATS tags is Deng et al. [17]. This study found that the group with injectable tags had higher survival probability through the $500 \mathrm{~km}$ study area compared to the group with the standard tag. The Deng (2017) study used fish much larger than our study (mean FL of $110 \mathrm{~mm}$ compared to $87 \mathrm{~mm}$ ), suggesting that larger fish may benefit from the reduced 
weight of the injectable tag relative to the standard tag, while not experiencing any negative effects from its increased length. The results from our study suggest that, in smaller fish, there may be a maximum tag burden by length where below which there are negative impacts on survival and growth. Perhaps larger fish have body cavities able to accommodate the longer injectable tag with relatively fewer negative consequences, but in the body cavity of relatively small Chinook (i.e., $87 \mathrm{~mm} \mathrm{FL),} \mathrm{the} \mathrm{tag}$ could impinge on internal organs and decrease stomach capacity, thus decreasing growth.

Reduced growth in acoustic tagged fish has been reported in other studies [5, 47]. In juvenile salmon implanted with acoustic tags, reduced growth may reduce survival relative to untagged fish. Field studies of juvenile salmon have shown size selective mortality, where larger and faster swimming juvenile salmon showed increased survival compared to smaller fish after entering the ocean [35, 54]. Additionally, hatchery-released Chinook salmon survival to maturity has been linked to a larger size when entering the ocean as juveniles [10]. As new tag types are developed, future studies may need to further investigate how tag shape and size affects fish growth and other factors related to survival.

In our study, two surgeons of vastly different experience were used to implant tags into study fish, and we defined experience as the number of tag implantation surgeries an individual had performed on similar fish species. The expert surgeon had performed thousands of tag implantation procedures while the novice had minimal experience in tag implantation. Although tag loss was similar for the surgeons, the five tagged fish that died in the study were tagged by the novice surgeon, while the two control fish mortalities were handled by the expert surgeon. This could be due to longer surgery times for the fish tagged by the novice surgeon, or less skill with the surgical procedure that led to increased physical trauma. There is some indication that growth in the injectable tagged fish was lower for the novice surgeon, but the difference was not statistically significant and should be further tested. Other studies have also reported a surgeon effect $[12,18]$. Our findings suggest that surgeon experience can influence survival in acoustic tagged fish and implies that novice surgeons should be properly trained prior to conducting surgeries for acoustic telemetry studies.

Estimating survival rates of juvenile fish using acoustic telemetry is a highly effective tool for fisheries management. However, understanding how the tagging process affects tag retention and fish growth is critical in estimating survival rates of study fish. Tag shedding can be a significant factor in altering survival estimates, with some laboratory studies having up to $37 \%$ of fish displaying partial to complete tag shedding after 30 days [20]. The results from our study indicate that tag retention and growth in juvenile Chinook salmon is primarily influenced by water temperature and tag type, respectively, with some evidence that tag burden by length may play an important role in determining tag shedding. Because these factors are unlikely to remain constant among studies using acoustic transmitters, it is vital that each study also monitor a subsample of fish implanted with identical transmitters for tag retention, growth and survival under temperatures that match those observed in the field. The information from these trials is analogous to tag-failure times and can be used to correct survival estimates from field studies $[29,44,45,48]$. Obtaining accurate survival estimates is critical in making well-informed management decisions, which has implications for the recovery of both hatchery and wild salmonid populations in the $\mathrm{CCV}$.

\section{Acknowledgements}

We thank Anna Kastner of the California Department of Fish and Wildlife's Feather River State Fish Hatchery for providing the fish for this study. We thank Erick Sturm and Joshua Meko for support with fish husbandry and aquarium maintenance. We thank K. Pipal for editorial comments on the manuscript. Reference to trade names does not imply endorsement by the U.S. Government.

\section{Authors' contributions}

JN, RRR, and AJA conceived of the study. JN and AJA funded the research. RRR, $A M, R L$, and TP carried out the experiment. RRR performed the analyses. RRR wrote the paper, and all authors contributed to the final edits of the manuscript. All authors read and approved the final manuscript.

\section{Funding}

Funding for this work was provided by the USFWS (F19PG00040) and a grant to the University of California at Santa Cruz (Grant 18-0418).

\section{Availability of data and materials}

The datasets used and/or analyzed during the current study are available from the corresponding author on reasonable request.

\section{Declarations}

\section{Ethics approval and consent to participate}

All work with fish was reviewed and approved by the University of California's Institutional Animal Care and Use Committee (Kierj1604_a3), California Department of Fish and Wildlife permit SC-13029 and NOAA Fisheries Section 10 permit 17299-3M.

\section{Consent for publication}

Not applicable.

\section{Competing interests}

The authors declare that they have no competing interests.

\section{Author details}

${ }^{1}$ Institute of Marine Sciences, University of California, Santa Cruz, USA. ${ }^{2}$ Southwest Fisheries Science Center, National Marine Fisheries Service, 110 McAllister Way, Santa Cruz, CA 95060, USA.

Received: 12 February 2021 Accepted: 9 June 2021

Published online: 21 June 2021 


\section{References}

1. Ammann AJ, Michel CJ, MacFarlane RB. The effects of surgically implanted acoustic transmitters on laboratory growth, survival and tag retention in hatchery yearling Chinook salmon. Environ Biol Fishes. 2013:96(2-3):135-43.

2. Anglea SM, Geist DR, Brown RS, Deters KA, McDonald RD. Effects of acoustic transmitters on swimming performance and predator avoidance of juvenile chinook salmon. North Am J Fish Manag. 2004;24(1):162-70.

3. Beardsall JW, Mclean MF, Cooke SJ, Wilson BC, Dadswell MJ, Redden AM, Stokesbury MJW. Consequences of incidental otter trawl capture on survival and physiological condition of threatened Atlantic Sturgeon. Trans Am Fish Soc. 2013;142(5):1202-14.

4. Braun CD, Skomal GB, Thorrold SR, Berumen ML. Movements of the reef manta ray (Manta alfredi) in the Red Sea using satellite and acoustic telemetry. Marine Biol. 2015;162(12):2351-62.

5. Brown RS, Harnish RA, Carter KM, Boyd JW, Deters KA, Eppard MB. An evaluation of the maximum tag burden for implantation of acoustic transmitters in juvenile chinook salmon. North Am J Fish Manag. 2010;30(2):499-505

6. Buchanan RA, Brandes PL, Skalski JR. Survival of juvenile fall-run chinook salmon through the San Joaquin River Delta, California, 2010-2015. North Am J Fish Manag. 2018;38(3):663-79.

7. Buchanan RA, Skalski JR, Brandes PL, Fuller A. Route use and survival of juvenile chinook salmon through the San Joaquin River Delta. North Am J Fish Manag. 2013;33(1):216-29.

8. Bunnell DB, Isely JJ. Influence of temperature on mortality and retention of simulated transmitters in Rainbow trout. North Am J Fish Manag. 1999;19(1):152-4.

9. Cerutti-Pereyra F, Thums M, Austin CM, Bradshaw CJA, Stevens JD, Babcock RC, Pillans RD, Meekan MG. Restricted movements of juvenile rays in the lagoon of Ningaloo Reef, Western Australia - evidence for the existence of a nursery. Environ Biol Fishes. 2014;97(4):371-83.

10. Claiborne AM, Fisher JP, Hayes SA, Emmett RL. Size at Release, size-selective mortality, and age of maturity of Willamette River hatchery yearling chinook salmon. Trans Am Fish Soc. 2011;140(4):1135-44.

11. Collins AL, Hinch SG, Welch DW, Cooke SJ, Clark TD. Intracoelomic acoustic tagging of juvenile sockeye salmon: swimming performance, survival, and postsurgical wound healing in freshwater and during a transition to seawater. Trans Am Fish Soc. 2013;142(2):515-23.

12. Cooke SJ, Graeb BDS, Suski CD, Ostrand KG. Effects of suture material on incision healing, growth and survival of juvenile largemouth bass implanted with miniature radio transmitters: Case study of a novice and experienced fish surgeon. J Fish Biol. 2003;62(6):1366-80.

13. Cordoleani F, Notch J, MCHuron AS, Ammann AJ, Michel CJ. Movement and survival of wild chinook salmon smolts from Butte Creek during their out-migration to the ocean: comparison of a dry year versus a wet year. Trans Am Fish Soc. 2018;147(1):171-84.

14. Crossin GT, Heupel MR, Holbrook CM, Hussey NE, Lowerre-Barbieri SK, Nguyen VM, Raby GD, Cooke SJ. Acoustic telemetry and fisheries management. Ecol Appl. 2017;27(4):1031-49.

15. Delta Juvenile Fish Monitoring Program - Chipps Island trawls CHN-POD species 2012-Present. (n.d.). . https://www.fws.gov/lodi/juvenile_fish_ monitoring_program/difmp/?dir=Chipps Island trawls CHN-POD species 2012-Present

16. Deng ZD, Carlson TJ, Li H, Xiao J, Myjak MJ, Lu J, Martinez JJ, Woodley CM, Weiland MA, Eppard MB. An injectable acoustic transmitter for juvenile salmon. Sci Rep. 2015;5(1):8111.

17. Deng ZD, Martinez JJ, Li H, Harnish RA, Woodley CM, Hughes JA, Li X, Fu T, Lu J, McMichael GA, Weiland MA, Eppard MB, Skalski JR, Townsend $\mathrm{RL}$. Comparing the survival rate of juvenile Chinook salmon migrating through hydropower systems using injectable and surgical acoustic transmitters. Sci Rep. 2017;7:4299.

18. Deters KA, Brown RS, Carter KM, Boyd JW, Eppard MB, Seaburg AG. Performance assessment of suture type, water temperature, and surgeon skill in juvenile chinook salmon surgically implanted with acoustic transmitters. Trans Am Fish Soc. 2010;139(3):888-99.

19. Fischer ES, Blackburn SE, Liss SA, Hughes JS, Li H, Deng ZD. How small can we go? Evaluating survival, tag retention, and growth of juvenile chinook salmon implanted with a new acoustic microtag. North Am J Fish Manag. 2019;39(6):1329-36
20. Frost DA, McComas RL, Sandford BP. The effects of a surgically implanted microacoustic tag on growth and survival in subyearling fall chinook salmon. Trans Am Fish Soc. 2010;139(4):1192-7.

21. Geist DR, Liss SA, Harnish RA, Deters KA, Brown RS, Deng ZD, Martinez JJ, Mueller RP, Stephenson JR. Juvenile chinook salmon survival when exposed to simulated dam passage after being implanted with a new microacoustic transmitter. North Am J Fish Manag. 2018:38(4):940-52.

22. Heupel MR, Simpfendorfer CA. Estimation of mortality of juvenile blacktip sharks, Carcharhinus limbatus, within a nursery area using telemetry data. Can J Fish Aquat Sci. 2002;59(4):624-32.

23. Hopkins KD. Reporting fish growth: A review of the basics. J World Aquac Soc. 1992;23(3):173-9.

24. Jakobs S, Braccini M. Acoustic and conventional tagging support the growth patterns of grey nurse sharks and reveal their large-scale displacements in the west coast of Australia. Marine Biol. 2019;166(11):1-5.

25. Jepsen N, Mikkelsen JS, Koed A. Effects of tag and suture type on survival and growth of brown trout with surgically implanted telemetry tags in the wild. J Fish Biol. 2008;72(3):594-602.

26. Lacroix GL, Knox D, McCurdy P. Effects of implanted dummy acoustic transmitters on juvenile Atlantic salmon. Trans Am Fish Soc. 2004;133(1):211-20

27. Liss SA, Brown RS, Deters KA, Walker RW, Deng ZD, Eppard MB, Townsend $\mathrm{RL}$, Seaburg AG. Mortality, transmitter retention, growth, and wound healing in juvenile salmon injected with micro acoustic transmitters. Trans Am Fish Soc. 2016;145(5):1047-58.

28. McMichael GA, Eppard MB, Carlson TJ, Carter JA, Ebberts BD, Brown RS, Weiland M, Ploskey GR, Harnish RA, Deng ZD. The juvenile salmon acoustic telemetry system: a new tool. Fisheries. 2010;35(1):9-22.

29. McMichael GA, Skalski JR, Deters KA. Survival of juvenile chinook salmon during barge transport. North Am J Fish Manag. 2011;31(6):1187-96.

30. Melnychuk MC, Dunton KJ, Jordaan A, McKown KA, Frisk MG. Informing conservation strategies for the endangered Atlantic sturgeon using acoustic telemetry and multi-state mark-recapture models. J Appl Ecol. 2017;54(3):914-25.

31. Michel CJ, Ammann AJ, Chapman ED, Sandstrom PT, Fish HE, Thomas MJ, Singer GP, Lindley ST, Klimley AP, MacFarlane RB. The effects of environmental factors on the migratory movement patterns of Sacramento River yearling late-fall run Chinook salmon (Oncorhynchus tshawytscha). Environ Biol Fishes. 2013;96(2-3):257-71

32. Michel CJ, Ammann AJ, Lindley ST, Sandstrom PT, Chapman ED, Thomas MJ, Singer GP, Klimley AP, MacFarlane RB. Chinook salmon outmigration survival in wet and dry years in California's Sacramento river. Can J Fish Aquat Sci. 2015;72(11):1749-59.

33. Moore A, Russell IC, Potter ECE. The effects of intraperitoneally implanted dummy acoustic transmitters on the behaviour and physiology of juvenile Atlantic salmon, Salmo salar L. J Fish Biol. 1990;37(5):713-21.

34. Le Morvan C, Troutaud D, Deschaux P. Differential effects of temperature on specific and nonspecific immune defences in fish. J Exp Biol. 1998:201(2):165-8.

35. Moss JH, Beauchamp DA, Cross AD, Myers KW, Farley EV, Murphy JM, Helle $\mathrm{JH}$. Evidence for size-selective mortality after the first summer of ocean growth by pink salmon. Trans Am Fish Soc. 2005;134(5):1313-22.

36. Notch JJ, MCHuron AS, Michel CJ, Cordoleani F, Johnson M, Henderson MJ, Ammann AJ. Outmigration survival of wild Chinook salmon smolts through the Sacramento River during historic drought and high water conditions. Environ Biol Fishes. 2020;103:1-16.

37. Panther JL, Brown RS, Gaulke GL, Deters KA, Woodley CM, Brad Eppard M. Influence of incision location on transmitter loss, healing, survival, growth, and suture retention of juvenile Chinook salmon. Trans Am Fish Soc. 2011;140(6):1492-503.

38. Pendleton RM, Standley CR, Higgs AL, Kenney GH, Sullivan PJ, Sethi SA, Harris BP. Acoustic telemetry and benthic habitat mapping inform the spatial ecology of shortnose sturgeon in the Hudson River, New York, USA. Trans Am Fish Soc. 2019;148(1):35-47.

39. Perry RW, Skalski JR, Brandes PL, Sandstrom PT, Klimley AP, Ammann A, MacFarlane B. Estimating survival and migration route probabilities of juvenile chinook salmon in the Sacramento-San Joaquin River Delta. North Am J Fish Manag. 2010;30(1):142-56.

40. Plumb JM, Adams NS, Perry RW, Holbrook CM, Romine JG, Blake AR, Burau JR. Diel activity patterns of juvenile late Fall-run Chinook salmon with 
implications for operation of a gated water diversion in the SacramentoSan Joaquin river Delta. River Res Appl. 2015;32(4):711-20.

41. Ramsden S, Cotton CF, Curran MC. Using acoustic telemetry to assess patterns in the seasonal residency of the Atlantic stingray Dasyatis sabina. Environ Biol Fish. 2017;100(2):89-98.

42. Rechisky, E. L., and D. W. Welch. 2010. Surgical implantation of acoustic tags: Influence of tag loss and tag-induced mortality on free-ranging and hatchery-held spring Chinook Salmon (Oncorhynchus tshawytscha) smolts. PNAMP Special Publication: tagging, telemetry and marking measures for monitoring fish populations 2(May 2018):71-96.

43. del Rosario RB, Redler YJ, Newman K, Brandes P, Sommer T, Reece K, Vincik R. San Francisco estuary and watershed science migration patterns of juvenile winter-run-sized chinook salmon (Oncorhynchus tshawytscha) through the Sacramento - San Joaquin Delta. San Francisco Estuary and Watershed Science 2013;11(1).

44. Sandstrom PT, Ammann AJ, Michel C, Singer G, Chapman ED, Lindley S, MacFarlane RB, Klimley AP. Growth, survival, and tag retention of steelhead trout (Oncorhynchus mykiss) and its application to survival estimates. Environ Biol Fishes. 2013;96(2-3):145-64.

45. Skalski JR, Whitlock SL. Vitality models found useful in modeling tag-failure times in acoustic-tag survival studies. Animal Biotelem. 2020;8(1):1-10.

46. Tickler DM, Carlisle AB, Chapple TK, Curnick DJ, Dale JJ, Schallert RJ, Block BA. Potential detection of illegal fishing by passive acoustic telemetry. Animal Biotelem. 2019;7(1):1-11.

47. Towne K, and P. L. Brandes. 2018. Survival, tag retention, growth, and wound healing of juvenile chinook salmon (Oncorhynchus tshawytscha) surgically implanted with a dummy acoustic tag. San Francisco Estuary and Watershed Science 16(3).

48. Townsend RL, Skalski JR, Dillingham P, Steig TW. Correcting bias in survival estimation resulting from tag failure in acoustic and radiotelemetry studies. J Agric Biol Environ Stat. 2006;1 (2):183-96.
49. Tyus HM. Long-term retention of implanted transmitters in Colorado Squawfish and Razorback Sucker. North Am J Fish Manag. 1988:8(2):264-7.

50. Walker RW, Ashton NK, Brown RS, Liss SA, Colotelo AH, Beirão BV, Townsend RL, Deng ZD, Eppard MB. Effects of a novel acoustic transmitter on swimming performance and predator avoidance of juvenile Chinook Salmon: Determination of a size threshold. Fish Res. 2016;176:48-54.

51. Walsh MG, Bjorgo KA, Jeffery Isely J. Effects of implantation method and temperature on mortality and loss of simulated transmitters in hybrid striped bass. Trans Am Fish Soc. 2000;129(2):539-44.

52. Wargo Rub MA, Sandford BP, Butzerin JAM, Cameron AS. Pushing the envelope: micro-transmitter effects on small juvenile Chinook salmon (Oncorhynchus tshawytscha). PLoS ONE. 2020;15(3):1-21.

53. Welch DW, Rechisky EL, Melnychuk MC, Porter AD, Walters CJ, Clements S, Clemens BJ, McKinley RS, Schreck C. Survival of migrating salmon smolts in large rivers with and without dams. PLoS Biol. 2008;6(10):2101-8.

54. Woodson LE, Wells BK, Weber PK, MacFarlane RB, Whitman GE, Johnson RC. Size, growth, and origin-dependent mortality of juvenile Chinook salmon Oncorhynchus tshawytscha during early ocean residence. Mar Ecol Prog Ser. 2013;487:163-75

55. Yoshiyama RM, Fisher FW, Moyle PB. Historical abundance and decline of Chinook Salmon in the Central Valley Region of California. North Am J Fish Manag. 1998;18(3):487-521.

\section{Publisher's Note}

Springer Nature remains neutral with regard to jurisdictional claims in published maps and institutional affiliations.
Ready to submit your research? Choose BMC and benefit from:

- fast, convenient online submission

- thorough peer review by experienced researchers in your field

- rapid publication on acceptance

- support for research data, including large and complex data types

- gold Open Access which fosters wider collaboration and increased citations

- maximum visibility for your research: over $100 \mathrm{M}$ website views per year

At BMC, research is always in progress.

Learn more biomedcentral.com/submissions 